\title{
Basic Workshop Personal Leadership For Student
}

\author{
Agus Fahmi ${ }^{1}$, Hardiansyah ${ }^{2}$, Lukmanul Hakim ${ }^{3}$, Lu`luin Najwa ${ }^{4}$ \\ Program Studi Administrasi Pendidikan FIPP UNDIKMA \\ Coresponding Author: fahmi_ap@ikipmataram.ac.id
}

\begin{abstract}
Specifically in educational activities many schools learning centers and tertiary institutions stand in a variety of forms and fields of science. In the last decade there has been a decline in the value of leadership, especially for adolescents, in this case high school-age children who, when examined more deeply, found disciplinary attitudes, apathy, lack of social sense, and deteriorating educational achievement. The effect of this is the decreasing level of HDI (Human Development Index) of NTB. Based on data releases from BPS, it turns out that since 2010 NTB has been ranked 29th out of 33 provinces in Indonesia. Unfortunately since 2013 it has dropped back to 30 th out of 34 provinces in Indonesia (BAPPEDA NTB: 2020). Therefore, it is important to provide knowledge and leadership training early on to teenagers through a Workshop with the theme Personal Leadership For Student in the hope that this training provides insight into the importance of having a leadership spirit that is supported by high motivation and confidence. Besides that, basic leadership training for students can also become routine and permanent schedule in schools so that the knowledge of leadership is not only an insight but also a soft skill values that are embedded in the character of young people who will lead in the future.
\end{abstract}

Keywords: Personal leadership, student

Abstrak: Khusus pada kegiatan pendidikan berdiri kokoh banyak sekolah, pusat belajar, dan perguruan tinggi dengan berbagai macam bentuk dan bidang keilmuan. Pada dekade terakhir telah terjadi kemerosotan nilai kepemimpinan terutama bagi kalangan remaja dalam hal ini anak-anak usia sekolah menengah yang bila dikaji lebih dalam ditemukan sikap indisipliner, apatis, kurangnya sense of social, dan semakin merosotnya prestasi pendidikan. Efek yang diakibatkan dari hal tersebut adalah semakin menurunnya tingkat IPM (Indeks Pembangunan Manusia) NTB. Berdasarkan rilis data dari BPS ternyata sejak tahun 2010 posisi NTB sudah berada di urutan ke-29 dari 33 Provinsi yang ada di Indonesia. Sayangnya sejak tahun 2013 turun kembali ke urutan 30 dari 34 provinsi di Indonesia (BAPPEDA NTB: 2020). Oleh karena itu, penting untuk diberikan pengetahuan dan pelatihan kepemimpinan sejak dini kepada para remaja melalui sebuah Workshop dengan tema Personal Leadership For Student dengan harapan bahwa pelatihan ini memberikan wawasan secara mendalam tentang pentingnya memiliki jiwa kepemimpinan yang ditopang oleh kemampuan motivasi dan kepercayaan diri yang tinggi. Disamping itu, pelatihan dasar kepemimpinan pada siswa juga dapat menjadi rutinitas dan permanent schedule dalam sekolah sehingga pengetahuan tentang kepemimpinan ini, tidak hanya sebagai wawasan saja tetapi juga merupakan nilai-nilai softskill yang tertanam dalam karakter para generasi muda yang akan memimpin di masa yang akan datang.

Kata Kunci: Personal leadership, student

\section{PENDAHULUAN}

Latihan dasar kepemipinan siswa LDKS atau personal leadership for student adalah sebuah bentuk kegiatan yang bertolak ukur kepada peningkatan sumber daya siswa dan siswi peserta untuk mendalami dan memahami tentang konsep-konsep atau dasar
- dasar sebuah organisasi di sekolah. LDKS ini untuk Menanamkan jiwa kepemimpinan, kemandirian, dan keteladanan kepada siswa.

Manfaat mengikuti LDKS bagi siswa yaitu siswa dapat memperoleh atau melakukan diantaranya :

Peserta mengetahui bahwa setiap diri 
harus mampu memimpin diri terlebih dahulu.

Setelah mendapatkan materi tentang kepemimpinan, siswa mengetahui bahwa setiap diri harus mampu memimpin diri terlebih dahulu sebelum ia menjadi pemimpin untuk orang lain dan organisasi.

a. Peserta mampu berpikr positif terhadap dirinya sendiri, disiplin dalam segala hal, antusias, dan senantiasa sportif dalam berbagai kondisi apapun.

b. Peserta mampu membentukan Tim Dengan belajar keterampilan untuk membangun tim, para siswa memperoleh praktek berharga dalam bekerja sama dengan orang lain dalam posisi manajemen. Seorang pemimpin harus mampu untuk menetapkan tujuan tertentu dan kemudian memberikan arah tertentu untuk melaksanakan tujuan tersebut; dalam melakukannya, ia juga belajar keterampilan mendelegasikan tanggung jawab. Belajar seni mendengarkan orang lain dalam tim dan menanggapi dengan fleksibilitas ketika diperlukan adalah praktek yang bagus untuk peran kepemimpinan masa depan di setting apapun.

c. Dapat Memanfaatkan Sumber Daya Masukan dalam posisi kepemimpinan, seorang siswa dapat dengan cepat mempelajari cara menemukan dan menggunakan sumber daya untuk membantu melaksanakan tujuannya. Dalam pengaturan sekolah, pemimpin mungkin perlu mencari saran dan atau bantuan dari guru serta kepala sekolah.

d. Membangun Kepercayaan Diri Siswa di latih untuk berbicara di depan umum dan untuk berkomunikasi dengan berbagai individu, keuntungan dalam kepercayaan diri yaitu untuk belajar ketegasan, belajar untuk mengatakan "tidak" bila diperlukan, belajar bertekun dalam menghadapi kesulitan semua keterampilan yang menambah kepercayaan diri seseorang. Seringkali, kemauan untuk mengambil risiko dalam posisi naik karena kepercayaan pemimpin siswa dalam dirinya meningkat.

e. Dapat Memprioritaskan Siswa dalam posisi kepemimpinan belajar dengan cepat bahwa mereka harus memprioritaskan dalam situasi apapun. Belajar bagaimana melakukan hal ini itu, bagaimanapun membutuhkan latihan. Mengingat cukup waktu siswa belajar keterampilan prioritas yang memberikan berapa banyak waktu untuk, apa yang harus menghabiskan waktu paling banyak dan sebagainya - yang akan berdiri dalam manfaat yang baik untuk tahun mendatang. Memprioritaskan melibatkan beberapa jenis visi bagi organisasi dan mengetahui bagaimana untuk mengarahkan semua orang ke arah yang benar.

Manfaat LDKS ini dapat dirasakan para siswa setelah mereka selesai mengikuti pelatihan tersebut. Dan manfaat tersebut berpengaruh pada kepribadian mereka dan juga dapat dirasakan saat mereka masuk kedalam sebuah organisasi. Baik organisasi sekolah maupun organisasi masyarakat.

\section{Metode Pengabdian}

Metode yang diterapkan dalam pelatihan ini, yaitu metode presentasi, metode demonstrasi, dan metode praktik. Metode presentasi dalam kegiatan ini untuk menjelaskan teori dan perspektif ilmiah tentang pentingnya personal leadership. Metode Demonstrasi bertujuan untuk mengenal karakteristik masing-masing siswa yang menjadi peserta workshop. Sedangkan metode praktik dimaksudkan untuk menggali kemampuan dan spesifikasi pemahaman siswa dalam mengimplementasikannya secara nyata.

\section{HASIL \\ PENGABDIAN \\ DAN \\ PEMBAHASAN}

1. Persiapan

1) Mekanisme pelaksanaan kegiatan PKM

2) Persiapan Materi Basic Workshop Personal Leadership For Student

3) Pembuatan Modul

2. Pelaksanaan Program

Adapun pelaksanaan kegiatan

Pengabdian ini adalah sebagai berikut:

a. Melakukan analisis tentang aktivitas Sekolah

b. Analisis masalah sekolah

c. Penyusunan modul diklat

d. Perbanyakan modul sesuai dengan jumlah peserta.

e. Program Pelatihan Basic Workshop Personal Leadership For Student yang pertama adalah proses perkenalan dan pemberian materi diklat. Kegiatan matrikulasi dilakukan 1 kali 
pertemuan dengan waktu 4 jam untuk setiap pertemuan.

f. Pelaksanaan Kegiatan mandiri dengan pola kerja yang telah dipelajari.

g. Kegiatan evaluasi perkembangan program

h. Program monitoring

i. Volume pelaksaan PKM yang dilakukan.
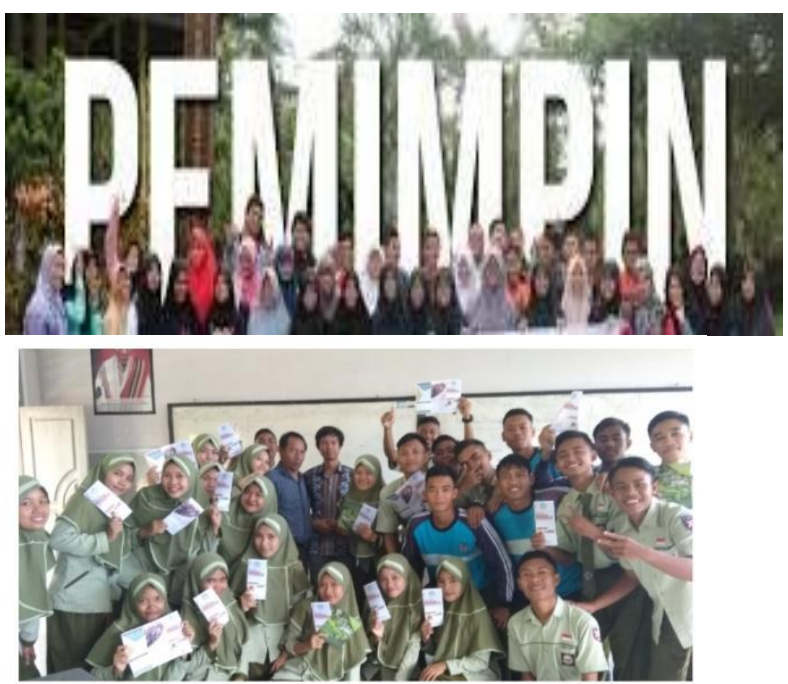

Gambar. Dokumentasi Kegiatan Workshop

Permainan-permainan yang memiliki nilai kepemimpinan, seperti :

a. Memasukkan paku dalam botol dengan mata tertutup. Salah seorang yang lain memberikan aba-aba agar paku tersebut masuk. Dibutuhkan kemampuan untuk menganalisis segala macam kemungkinan dan kemampuan untuk memerintah secara hati-hati dan terpertimbangkan agar bisa mencapai goal dari permainan ini yaitu memasukkan paku dalam botol.

b. Bisik berantai. Dibutuhkan kemampuan sebagai pendengar sekaligus penyampai pesan yang baik agar dapat menyampaikan pesan yang benar dari awal hingga akhir.

Pemberian materi kepemimpinan yang dibagi dalam beberapa sesi, seperti :

a. Sesi Kepemimpinan : Penyuluhan mengenai karakter pemimpin yang benar.

b. Sesi Komunikasi : Penyuluhan mengenai cara-cara berkomunikasi yang benar sebagai layaknya seorang pemimpin.

c. Sesi Problem Solving / Challange - Proses manajemen konflik : Penyuluhan mengenai cara-cara seorang pemimpin memecahkan masalah secara efektif dan benar.

d. Sesi Dinamika Kelompok : Berupa permainan.

Pelaksanaan program pengabdian tentang personal leadership merupakan pembentukan karakter pemimpin sejak usia muda. Sehingga dapat berperan aktif baik di lingkungan kelas, sekolah, keluarga, dan di lingkungan masyarakat. Terlebih lagi, penemuan jati diri, kedisiplinan, penghargaan, daya juang, kerja sama, tanggung jawab, kerendahan hati dan motivasi serta komitmen pribadi.

Tujuan diadakannya latihan kepemimpinan dasar ini adalah :

1. Siswa dapat mengenali jati dirinya : kelemahan dan kekuatan dirinya.

2. Siswa dapat mengenal pribadi orang lain dan mampu menempatkan diri di hadapan orang lain dengan baik dan bertanggung jawab.

3. Siswa menyadari akan sikap hidup yang positif

4. Siswa mampu menyusun langkah-langkah nyata bagi hidupnya dalam rangka untuk menjadi pemimpin bagi dirinya sendiri.

\section{PEMBAHASAN}

Untuk mengawali kegiatan workshop Personal Leadership For Student diberikan pemahaman yakni dalam tingkatan ilmiah kepemimpinan itu dipandang sebagai suatu fungsi, bukan sebagai kedudukan atau pembawaan pribadi seseorang. Maka diadakanlah suatu analisa tentang unsur-unsur dan fungsi yang dapat menjelaskan kepada kita, syarat-syarat apa yang diperlukan agar pemimpin dapat bekerja secara efektif dalam situasi yang berbeda-beda. Pandangan baru ini membawa perubahan besar. Cara bekerja dan sikap seorang pernimpin dipelajari. Cara melatih pemimpin-pemimpin diubah. Orang mempelajari lebih banyak aspek kehidupan dalam kelompok. Ada yang memusatkan perhatian terhadap hubungan insani dalam kelompok. Ada pula yang memperhatikan organisasi kelompok, aspek perasaan atau emosi, struktur kekuasaan dan wibawa antar anggota, proses pengambilan keputusan, pola komunikasi, fungsi pemimpin dan yang dipimpin. 
Level Konseptualisasi Kepemimpinan

1) Proses Individual

Potensi kontribusi dari pendekatan intra individu terhadap kepemimpinan sangatlah terbatas, karena tidak mencakup sebagian besar teori yang dianggap merupakan proses penting dari kepemimpinan, yaitu pengaruh atas orang lain. Dalam studi tentang ciri kepemimpinan yang tidak membahas perilaku pemimpin dan proses pengaruh, sulit menentukan mengapa beberapa ciri atau keterampilan itu berhubungan dengan efektivitas atau kemajuan kepemimpinan. Pengetahuan tentang proses intra individu memberikan beberapa pemahaman yang membantu dalam menyusun teori kepemimpinan yang lebih baik, tetap teori itu sendiri sebaiknya tidak berfokus pada level ini.

2) Proses Dyadic

Fokus dari pendekatan dyadic adalah pada hubungan antara seorang pemimpin dan individu lain yang biasanya merupakan seorang pengikut. Sebagian besar teori dyadic memandang kepemimpinan sebagai proses pengaruh timbal balik antara pemimpin dengan orang lain.

3) Proses Kelompok

Pandangan lain mengenai kepemimpinan memandang kepemimpinan sebagai proses kelompok. Dua topik utamanya adalah sifat peran kepemimpinan dalam tugas kelompok dan bagaimana kontribusi pemimpin terhadap efektivitas kelompok.

4) Proses Organisasi

Kelangsungan hidup dan kemakmuran organisasi tergantung pada efektivitas adaptasi terhadap lingkungan, yang berarti berhasil memasarkan outputnya (barang dan jasa), memperoleh sumber yang dibutuhkan, dan menghadapi ancaman eksternal. Adaptasi membaik dengan mengantisipasi kebutuhan dan keinginan pelanggan, selalu meninjau tindakan dan rencana competitor, selalu mngevaluasi kemungkinan kendala dan ancaman, dan mengidentifikasi prosuk dan jasa yang dapat dipasarkan dimana organisasi mempunyai kemampuan unik untuk memenuhinya.
Pemberian materi kepemimpinan khususnya tentang personal leadership dapat diterima dengan baik oleh seluruh siswa yang mengikuti kegiatan workshop, sehingga ketajaman pemahaman dapat didalami secara komprehensif. Demikian juga ketika menjalankan sebuah oraganisasi sepeti Osis, Pramuka, UKS, dan seterusnya dapat menerapkan fungsi esensial kepemimpinan agar membantu organisasi beradaptasi dengan lingkungan dan mendapatkan sumber-sumber yang dibutuhkan untuk bertahan hidup. Tanggung jawab kepemimpinan disini adalah mendesain struktur organisasi yang tepat, menentukan hubungan kewenangan dan mengkoordinasikan proses antar spesialisasi sub-unit dalam organisasi.

Sebagai bahan evaluasi dalam pelatihan ini maka Muncul secara tidak langsung apabila ingin mengetahui apakah sebabnya seseorang yang dicalonkan untuk seorang pemimpin pada akhirnya tidak terpilih dalam hubungan ini ada dua pendapat tentang persyaratan menjadi pemimpin itu, yaitu sebagai berikut :

1. Bahwa setiap orang yang sudah dewasa dengan sendirinya dapat menjadi pemimpin dalam kelompok. Dewasa dalam hal ini diukur berdasarkan umurnya. Maksudnya, apabila akan ditentukan siapakah yang cocok untuk memimpin sebuah kelompok, maka dia yang tertua yang dipilih. Dipilihnya yang tertua sebagai pemimpin kelompok bisanya berdasarkan beberapa pertimbangan, antara lain:

a) Yang tertua mempunyai pengalaman terbanyak, sebab dia sudah lebih lama hidup dibandingkan dengan yang lainnya (pengalaman hidup). Pengalaman hidup yang lama dapat membentuk pribadi yang kuat, sehingga stabilitas emosional lebih mungkin terdapat pada orang yang tertua usianya. Stabilitas emosional merupakan salah satu syarat penting yang banyak dituntut oleh seorang pemimpin.

b) Yang tertua secara emosional memungkinkan seseorang anggota memperoleh perlindungan lebih-lebih 


$\begin{array}{lr}\text { dalam suasana } & \text { kebapak-an } \\ \text { (paternalistik) dimana } & \text { seorang } \\ \text { pemimpin } & \end{array}$

2. bahwa tidak setiap orang begitu saja bisa menjadi pemimpin melainkan hanya bisa dipercayakan kepada orang-orang tertentu saja. Pendapat ini menegaskan, bahwa seorang pemimpin itu bukan orang begitu saja, tetapi memang orang pilihan (selected). Jadi tidak hanya sekedar tua umur saja, melainkan masih banyak syarat lain yang harus dipenuhi, yang pada pokoknya yang menyebabkan orang-orang menaruh kepercayaan kepada orang tersebut untuk bisa memimpin. Ini disebabkan karena :

a) Orang yang mempunyai umur paling tua belum tentu mampu memimpin, berdasarkan umur sudah tentu yang tertua berarti yang terlama hidup, akan tetapi belum tentu hidupnya diisi dengan pengalaman-pengalaman yang secara kualitatif berguna untuk memimpin kelompok.

b) Seorang pemimpin itu "menentukan" arah dan proses perjalanan kelompok, sehingga tidak sembarang orang bisa memimpin (dipercaya memimpin). Jika tidak selektif dikhawatirkan arah dan proses kehidupan kelompok akan rusak.

\section{KESIMPULAN DAN SARAN}

Mendahului kegiatan dengan

memberikan pemahaman tentang konsep dasar kepemimpinan yang dapat membentuk karakter dan kepribadian Siswa sehingga mereka mampu menjadi pribadi yang berakhlak mulia, santun, cekatan dalam bertindak, berkomunikasi dengan baik, memiliki pendirian yang kuat, dan berani bertanggungjawab secara sosial dan organisasi. Workshop ini memberikan manfaat yakni: 1) Kepada siswa dalam menghadapi tantangan zaman yang semakin kompetitif diharapkan karakter personal leadership menjadi benteng kokoh sebagai penopang sendi-sendi kehidupannya. 2) Pengaplikasian nilai-nilai kepemimpinan yang ditunjukkan pada tingkah laku siswa baik di sekolah maupun dalam lingkungan keluarga dan masyarakat. 3) menjadi pribadi yang tangguh dan memiliki sense of the future atau dapat menyongsong masa depan yang lebih baik. Demikianlah kegiatan workshop ini dilaksanakan dengan sangat apresiatif dari pihak sekolah dan masyarakat yang menginginkan adanya kegiatan lanjutan, sehingga kontinuitas kegiatan ini dapat diterapkan pada setiap tingkatan Siswa setiap tahunnya.

\section{DAFTAR PUSTAKA}

Agung T.,Roy Johan,Wayan Gede Supartha dan I Gede Riana. 2014. Pengaruh Kepemimpinan

TransformasionalTerhadap Motivasi dan Kinerja Karyawan(Sudi Kasus Pada PT. Pandawa).

E-Jurnal Ekonomi dan Bisnis Universitas Udayana3.9 (2014) :533-550ISSN : 2337-3067. Fakultas Ekonomi dan Bisnis Universitas Udayana Bali.

Dale, Robert. D. 1992. Pelayan Sebagai Pemimpin. Gandum Mas. Malang.

Hadfield, S dan Hasson, G. 2013. Bersikap Tegas dalam Segala Situasi. Jakarta: BIP Kelompok Gramedia.

Iyeng Wiaputra.1981.Beberapa aspek Dalam Kepemimpinan Pendidikan. Jakarta: Bhratara

Maxwell, J.C. 2003. Time Out. Penyegaran Spiritual bagi para pemimpin. Mitra Media

Murdoko, E.W.H. 2013. The Leader in You. Jakarta: ElexMedia Komputindo 